\title{
A representação social da escravidão nos museus brasileiros: interfaces entre a Museologia e a História.
}

\author{
Janaina Cardoso de Mello ${ }^{1}$
}

\section{Resumo}

O artigo apresenta um estudo das representações da escravidão nos museus brasileiros em seus aspectos simbólicos, políticos e culturais na perspectiva de uma interface entre a Museologia e a História, refletindo sobre o papel político-cultural dos museus na sociedade brasileira. Assim, o estabelecimento de um diálogo com a produção historiográfica sobre a escravidão na sociedade brasileira permite discutir as representações sociais da escravidão nos museus brasileiros, com ênfase na realidade sergipana, para então se pensar novas possibilidades para uma expografia que contemple a pluralidade cultural afro-brasileira nos museus.

Palavras-chave: escravidão, museu, representação social.

\section{Abstract}

The article presents a study of representations of slavery in Brazilian museums in its symbolic, political and cultural aspects from the perspective of an interface between museology and history, reflecting the political and cultural role of museums in Brazilian society. Thus, the establishment of a dialogue with the historiographical production about slavery in Brazilian society lets discuss the social representations of slavery in Brazilian museums, with emphasis on the reality of Sergipe, to then think about new possibilities for a expographic covering the Afro-Brazilian cultural plurality in the museums.

Keywords: slavery, museum, social representation.

\section{Museu como lócus político-cultural, um debate preliminar.}

Mas quando nada subsiste de um passado antigo, depois da morte dos seres, depois da destruição das coisas, sozinhos, mais frágeis, porém, mais vivazes, mais imateriais, mais persistentes, mais fiéis, o aroma e o sabor permanecem ainda por muito tempo, como almas, chamando-se, ouvindo, esperando, sobre as ruínas de tudo o mais, levando sem se submeterem, sobre suas gotículas quase impalpáveis, o imenso edifício das recordações (Marcel Proust, 2004).

A sociedade civil tem exigido cada vez mais que o Estado lhe sacie a fome não apenas de comida, mas também sua fome de cultura, atuando de forma contundente na luta pelo reconhecimento de espaços diversificados que projetem memórias alternativas àquelas das elites em

\footnotetext{
${ }^{1}$ Profa .Dra.da Universidade Federal de Sergipe.
} 
seu relacionamento com o restante da sociedade. Assim, as memórias plurais, comunitárias, de grupos que há muito foram silenciados no processo de construção da narrativa histórica emergem com um potencial político-cultural agregador de novos sentidos. Desse modo, a noção de "museu", como lócus de comunicação com um público mais amplo, assim como os valores e representações transmutados nesses espaços culturais passaram por questionamentos em prol de uma maior diversidade e democratização.

Ao longo da década de 1960 os museus entraram na ordem do dia dos debates em torno da problematização do tempo histórico, principalmente no que tange a relação entre o presente e o passado. As interpretações tradicionais abordando os objetos históricos são criticadas enquanto expressões "naturalizadas" de um passado nacional uniforme e essencializado. A idéia de que o discurso museológico é produto de uma seleção feita com objetivos políticos e estéticos específicos, permeado por interesses particulares de determinados grupos torna o museu uma arena com acirradas disputas pelo poder (PIO, 2006).

Ao nos remetermos ao conceito de "lugares de memória" de Pierre Nora, percebemos a configuração dessa noção em:

museus, arquivos, cemitérios e coleções, festas, aniversários, tratados, processos verbais, monumentos, santuários, associações [...]. Pois, os lugares de memória nascem e vivem do sentimento que não há memória espontânea, que é preciso criar arquivos, que é preciso manter aniversários, organizar celebrações, pronunciar elogios fúnebres, notariar atas, porque essas operações não são naturais (NORA, 1993, p.13).

Lugares de memória e também de esquecimento seletivo, os museus desempenham um papel pedagógico junto aos cidadãos, independente das definições de educação e/ ou cidadania nas quais se baseiem. O caráter disciplinador dos museus modernos expressos no ordenamento do tempo e dos espaços visitados, na vigilância do patrimônio e na sacralização de objetos e culturas expostas configuram-se como mecanismos de controle sobre corpos e mentes. Assim, educar o indivíduo, estimular seu senso estético e afirmar o nacional compuseram durante muito tempo os objetivos principais das instituições museais (CHAGAS, 2001).

Cultuar a memória através de referenciais externos e coletivos, constituindo-os enquanto patrimônio afetivo de um grupo faz parte do próprio conceito de identidade quando da formação e do processo de consolidação dos Estados Nacionais modernos. Nesta direção, a noção de patrimônio assumia o status de instrumento que cumpria inúmeras funções simbólicas, tais como: 
[...]reforçar a noção de cidadania na medida em que são identificados, no espaço público, bens [...] a serem utilizados em nome do interesse público. Nesse caso, o Estado atua como guardião e gestor desses bens; ao partir da identificação, nos limites do Estado nacional, de bens representativos da nação [...] a noção de patrimônio contribui para objetivar, tornar visível e real, essa entidade ideal que é a nação [...]. A necessidade de proteger esse patrimônio comum reforça a coesão nacional; os bens patrimoniais [...] funcionam como documento das versões oficiais da história nacional, que constrói o mito de origem da nação e uma versão da ocupação do território, visando a legitimar o poder atual; a conservação desses bens - onerosa, complexa e freqüentemente contrária a outros interesses públicos e privados - é justificada por seu alcance pedagógico, a serviço da instrução dos cidadãos (FONSECA, 1997, pp.59-60).

Tanto na criação de consciências individuais, mas também na construção e representação de identidades coletivas diversas os museus interferem diretamente sobre a visão de mundo dos usuários de suas informações (COSTA, 2008). Territórios contestados, os museus tem passado por profundas revisões quanto à natureza de suas coleções (política de aquisição de acervos), as modalidades de representação cultural (expografia e expologia) e ao papel dos visitantes (estudo de público). Nesse processo a própria identidade e a missão dessas instituições estão sendo revisitadas através de estudos aprofundados, ressignificações e diálogos específicos da área museológica, mas também pelo viés de ações interdisciplinares (ANICO, 2005, pp.71-86).

Os museus históricos, em geral, impermeáveis às contendas sobre os usos e abusos do passado em suas narrativas lineares, permeadas por esquecimentos planejados de períodos de contraposição à "ordem” são pressionados pelos novos ventos de mudança. Há, entretanto, uma teatralização do passado nacional, quando o processo museográfico é obscurecido, projetando-se a perspectiva de uma viagem no tempo. Mas o monólogo discursivo das expografias não implica em silenciamentos reflexivos, uma vez que diferentes formas de recepção, apropriação e reconfiguração da mensagem são aplicadas pelos sujeitos no processo de ressignificação do conhecimento.

Os produtores das narrativas expográficas não detém o poder soberano na concepção de mensagens fechadas, que serão sempre decodificadas de maneira uniforme por todos os receptores; nem tais discursos se alicerçam em pressupostos comuns, muitas vezes de base ideológica, capazes de conduzir a interpretação. Todavia, deve-se levar em consideração que é através das relações de fronteira, das situações de interação, que os discursos sociais são construídos e apropriados (ENNE; TAVARES, 2004).

Compreender o tempo e o espaço vinculado à sociedade humana que constrói sua cultura perpassa o entendimento do "ofício do historiador" como a ação de pesquisadores que devem deixar de ser obcecados pelos relatos, visto que é impossível conhecer tudo a respeito do passado, 
buscando então um conhecimento através de vestígios, reconstruindo esse passado através de outras ciências afins (BLOCH, 2001).

Conforme afiançou Prost (2008) “o desafio que, daqui em diante, os historiadores devem enfrentar é o de transformar a demanda de memória de seus contemporâneos em história.” Assim, “o culto do passado responde à incerteza do futuro e à ausência de projeto coletivo. A derrocada das grandes ideologias - que, no plano político, constitui um progresso inegável da lucidez - deixa nossos contemporâneos sem referências." Sair da globalização que parece homogeinizar tudo e todos para estudar as singularidades de determinadas comunidades incorpora em si uma proposta de retorno ao particular e às identidades sociais ${ }^{2}$ em sua essência.

Ressalta-se o fato de que o significado é produzido e reproduzido dentro de determinada cultura. Por sua vez, a cultura é entendida como um conjunto de práticas que formam o sentido de ação, uma vez que incorpora um sujeito capaz de criar e agir sobre as coisas. Nessa compreensão remonta-se Geertz (1989) com seu conceito semiótico de cultura como uma ciência interpretativa em busca do significado - influenciada por Max Weber - para o qual o homem só é capaz de viver em um mundo que para si seja dotado de sentido. Desse modo, a cultura é uma teia de significados que os homens tecem e a ela se prendem, à medida que mantêm interações cotidianas que influem diretamente nas suas ações sociais. Igualmente, ela é como um texto ou um conjunto de textos que os indivíduos leem e interpretam ao longo dos acontecimentos sociais.

O conceito de cultura formulado por Geertz conflui com o conceito de representação, já que ambos partem da semiologia, também chamada de ciência geral dos signos, que estuda todos os fenômenos culturais com se fossem sistemas de signos ou de significação. Assim, a cultura não são cultos e costumes apenas, mas as estruturas de significado por meio das quais os indivíduos dão forma à sua experiência. Ressalta-se que a representação é uma construção ideológica e mental que se compartilha socialmente. Isto denota a própria interação que os indivíduos mantêm com a representação, tomada por meio da compreensão das estruturas e dos comportamentos sociais dos indivíduos (GEERTZ, 1989).

Apontando neste sentido, o historiador Roger Chartier disse que "as lutas de representações têm tanta importância como as lutas econômicas para compreender os mecanismos pelos quais um

\footnotetext{
${ }^{2}$ Recorrendo-se à Pollack (1992:7) para relacionar identidades sociais e memória, toma-se sua afirmação de que:
} 
grupo impõe, ou tenta impor, a sua concepção do mundo social, os valores que são os seus, o seu domínio" (CHARTIER, 2002, p.17). Segundo o próprio: “[...] pode pensar-se uma história cultural do social que tome por objecto a compreensão das formas e dos motivos - ou, por outras palavras, das representações do mundo social - que, à revelia dos actores sociais, traduzem as suas posições e interesses objectivamente confrontados e que paralelamente, descrevem a sociedade tal como pensam que ela é, ou como gostariam que fosse" (CHARTIER, 2002, p.19).

\section{Representações materiais da escravidão nos museus brasileiros: olhar sobre as instituições.}

Após o ano das comemorações do centenário da abolição da escravidão em 1988, a temática da arte afro-brasileira passou a ser mais discutida, gerando várias publicações, mas no início do século XX o assunto ainda era pouco explorado.

Raymundo Nina Rodrigues inaugurou o campo de estudos sobre arte negra com o artigo $A s$ Belas Artes nos Colonos Pretos do Brasil, publicado inicialmente na Revista Kosmos do Rio de Janeiro (1904). Nesse trabalho o autor analisou seis obras de arte negras: um "Oxê de Xangô" com representação masculina, uma estatueta de "sacerdote ou filho de santo", um "trono de Iemanjá", uma estatueta do "culto de Oxum, um Oxê de Xangô" com representação feminina e um "cofre atribuido a Iemanjá”’3.

A seleção das peças que fizeram parte do artigo de Nina Rodrigues incluiu apenas obras destinadas ao culto religioso, deixando à parte as obras populares e mesmo as eruditas produzidas por negros em Salvador, na Escola de Belas Artes da Bahia e Liceu de Artes e Ofícios, à exemplo de Antonio Firmino Monteiro e Antônio Rafael Pinto Bandeira. Esta seleção criou um paradoxo na história da arte afro-brasileira, condicionando a noção de que havia uma relação exclusiva entre a arte negra e a religião. A ruptura com essa idéia somente ocorreu com a exposição de 1997, denominada A mão afro-brasileira, onde artistas negros que produziram obras eruditas no século XIX foram historicizados e introduzidos na mostra como artistas afro-brasileiros, alguns contemporâneos de

\footnotetext{
${ }^{3}$ Somente em 1956, Arthur Ramos amplia o leque de obras abordadas no interior da arte afro-brasileira, incluindo artistas populares e que produziam obras laicas. Até então, o que se convencionava chamar de "arte afro-brasileira" era a produção ritualística e de origem iorubana e fon, tal como conceituou Nina Rodrigues (1988).
} 
Nina Rodrigues. Considerou-se para a inserção nesta categoria apenas o fato de serem negros e não a temática desenvolvida em suas obras (ARAÚJO, 1988).

Nina Rodrigues não compreendeu inteiramente a gramática formal da arte negra produzida na Bahia, mas é preciso que se diga que apesar de afirmações que hoje podemos apontar como resultantes de limitações relacionadas ao conhecimento da arte negra de então, reforçadas pelas teorias racistas vigentes, o seu mérito foi trazer à cena da época uma obra capital que iniciou uma tradição de estudos sobre a temática, permitindo que na atualidade seja possível uma visão do quadro da produção de cultura material afro-brasileira na virada do século XIX ao XX, dando visibilidade à presença negra na cultura e na arte brasileira de então e suas continuidades contemporâneas (CUNHA; NUNES; SANDES, 2006, p. 28).

Logo, a abordagem da escravidão nos museus necessita estabelecer um diálogo sobre os sentidos e as marcas legadas pela escravidão na sociedade brasileira, bem como as formas de representação social e material que estas adquirem ao longo do tempo. Apenas, dessa forma será possível

desvelar os corpos dos seres humanos, em sua multiplicidade de cores, tipos de cabelos, lábios, narizes e outros atributos físicos, traduzidos em valores sociais; a associação entre estes seres humanos e experiências históricas de seus semelhantes físicos e/ ou culturais; diferentes aproximações, em múltiplas experiências históricas, entre cor, raça, direitos e poderes (SILVA, 2007, p.92).

Ao pensar a cultura material de matriz africana no Brasil, a historiadora Kátia Mattoso (1997) em sua pesquisa sobre a Bahia do século XVIII, remonta a complexidade das relações sociais entre senhores e escravos, enfatizando o refinamento das roupas e dos adereços de alguns cativos, incluindo jóias de alto valor. Estes ornamentos caros estiveram em representações artísticas de pintores internacionais que estiveram no Brasil na época. Todavia, não é comum encontrar-se em museus e instituições culturais voltadas para uma expografia das tradições de matriz negra no Brasil, aqueles objetos de alto preço usados por determinados escravos. Porém, jóias e roupas de luxo que pertenceram a pessoas da elite branca, católica e latifundiária do mesmo período (uma baronesa, um ministro, alguns proprietários de escravos), fazem parte do acervo de importantes museus históricos brasileiros (SILVA, 2007, p.94)

Um primeiro entendimento sobre o paradoxo descrito diz respeito à relação de propriedade: as jóias não pertenciam aos escravos, pois os mesmos eram propriedades de outras pessoas. Os pertences que chegaram aos museus, em grande parte, foram doadas por herdeiros de seus 
proprietários originais, demonstrando suas vontades de perpetuação das memórias familiares (da árvore genealógica) e da necessidade do reconhecimento de raízes provenientes da nobreza. Houve casos de escravos que compraram a alforria e enriqueceram. É possível que alguns de seus pertences cheguem a museus, como objetos de pessoas livres e ricas, todavia sem menção à etnia negra como proprietária (SILVA, 2007, p.95).

A abordagem de Mattoso sobre o aspecto luxuoso de alguns escravos deve ser observada com merecido destaque, mesmo que não se possa confirmar com evidências materiais as jóias e roupas caras usadas por aqueles. O fato de não possuírem aqueles objetos e nem legá-los como herança aos seus descendentes, não inviabilizava o sentimento de satisfação pessoal, fruição estética e status social diferenciado dentre os demais escravos. O que em termos de representação social ou dramaturgia de festas litúrgicas de irmandades ou cívicas populares já demonstrava o entrosamento e o desejo de perteça a essa “órbis de esplendor".

Nos Maracatus, cortes negras se apresentavam e apresentam, em cortejo festivo, com roupas que remetem à suntuosidade e à riqueza. Uma exposição itinerante organizada pelo Ministério da Cultura, nos anos 90 do século XX, reuniu materiais de vários museus brasileiros, sob o título "Tesouros do Patrimônio". Uma das salas agrupou um vestido de dama da corte de Pedro II, um vestido de princesa do Maracatu, uma rica bandeja de prata e um instrumento de prender e torturar escravos. Esta seqüência, aparentemente desconexa, lembra-nos relações de natureza material (não haveria vestido de dama e bandeja sem os escravos) e de memória cultural (escravos podiam ver-se como pessoas belas e dignas de ornamentos que evocavam o direito ao esplendor, e seus descendentes biológicos e culturais podem preservar esta visão) (SILVA, 2007, p.95).

Alguns exemplos nós ajudam a atualizar a temática. Em 2007, foi inaugurado em Liverpool, um Museu Internacional da Escravidão, apresentando os fundamentos econômicos que ajudam a entender a história, possuindo para isso um acervo que explica a importância do tráfico de escravos para a Revolução Industrial. Sob outra perspectiva, buscando um resgate de povos oprimidos no processo colonialista oitocentista foi organizado um Museu Nacional da Escravatura em Angola (SLENES, 1995).

Nesse museu três módulos norteiam a representação social da escravidão sob a égide do colonialismo europeu: 1. Vida na África Ocidental - que se dispõe a questionar o que estava acontecendo na África, no momento do comércio e quem eram as pessoas envolvidas; 2. A escravidão e a Passagem do Meio - buscando transmitir uma lição sobre a brutalidade e o trauma sofrido por africanos escravizados na viagem através do Atlântico, e depois a opressão de suas vidas 
em plantações nas Américas; 3. Legados da escravidão - uma seção sobre a luta contínua pela liberdade e igualdade, olhando para os impactos/efeitos modernos da escravidão transatlântica, como o racismo e a discriminação sócio-econômica.

No Brasil, a experiência tem sido pontual. O Museu Afro-Brasileiro de Salvador - BA nasceu do Programa de Cooperação cultural entre o Brasil e países da África e para o desenvolvimento dos estudos voltados para a temática afro-brasileira, através de convênio firmado entre os Ministérios das Relações Exteriores e da Educação e Cultura, o Governo da Bahia, a prefeitura da cidade do Salvador e a Universidade Federal da Bahia (UFBA). Sua inauguração ocorreu em 7 de janeiro de 1982.

Inicialmente o Museu foi primeiro organizado por Pierre Verger, sendo instalado no prédio histórico da primeira Escola de Medicina do Brasil, de propriedade da Universidade Federal da Bahia, no Terreiro de Jesus. Em 1997, o Museu Afro-Brasileiro passou por um amplo processo de reestruturação atualizando a sua museografia e abordagem conceitual. O Centro de Estudos Afro-Orientais, órgão suplementar da Faculdade de Filosofia e Ciências Humanas da UFBA, tem sido o organismo responsável pelas atividades do Museu Afro-Brasileiro.

O acervo é composto por peças da cultura material de origem ou inspiração africana, representativas da vida cotidiana, dos processos tecnológicos, do sistema de crenças, das manifestações artísticas e da tradição oral na África tradicional. São esculturas, máscaras, tecidos, cerâmicas, adornos, instrumentos musicais, jogos e tapeçarias, provenientes do continente africano, adquiridos na década de 1970, pelo Ministério das Relações Exteriores, ou através de doações das diversas embaixadas dos países da África.

Há ainda objetos de origem brasileira, relacionados à religião afro-brasileira na Bahia, suas divindades e sacerdotes. São os atributos iconográficos e os adornos dos principais orixás e roupas de mães e pais-de santo de alguns terreiros de Salvador. Merece destaque especial o conjunto de talhas em cedro, do artista plástico Carybé, com dimensões monumentais (2 e 3 metros de altura) retratando 27 orixás e que constitui uma das mais importantes obras da arte contemporânea brasileira.

Em São Paulo, um importante e diversificado acervo formado por manifestações artísticas afro-brasileiras, com a história da resistência negra à escravidão e a trajetória de personalidades

\footnotetext{
${ }^{4}$ Hector Júlio Paride Bernabó nasceu na Argentina em 09 de fevereiro de 1911, fillho de pai italiano e mãe brasileira. $\mathrm{Na}$ infância morou na Itália mas, seu contato com o Brasil começou ainda na adolescência, quando, após a primeira guerra mundial, transferiu-se com a família para o Rio de Janeiro, onde permaneceu dos 8 aos 21 anos, regressando em seguida a Buenos Aires. Em 1938 realizou sua primeira viagem à Bahia e, a partir de 1950, retornou com a missão de desenhar a cidade, contratado pelo então Governador Otávio Mangabeira e se fixando definitivamente, tendo se naturalizado brasileiro e baiano alguns anos depois. Verdadeiro artista múltiplo - hábil em muitas artes realizou trabalhos em várias técnicas das artes plásticas. Distinguiu-se como desenhista, pintor, gravador, escultor, entalhador, muralista e ceramista. Carybé é o autor dos 27 painéis representando os orixás do candomblé da Bahia.
} 
desconhecidas tornam o Museu Afro Brasil uma experiência museológica única. Sob a direção do artista plástico Emanuel Araújo, o museu foi inaugurado em 2004, no Parque Ibirapuera, vinculado a Secretaria Municipal de Cultura, sendo também patrocinado pela Petrobrás.

Estão na exposição de longa duração a rica indumentária dos maracatus rurais, obras de artistas plásticos contemporâneos como Rubem Valentim e Mestre Didi, além das histórias de vida dos engenheiros André Rebouças e Teodoro Sampaio, do psiquiatra Juliano Moreira, documentos históricos e fotografias da época da escravidão. No museu, Araújo focaliza as questões da memória, e procura resgatar a trajetória de personalidades, como Carolina Maria de Jesus. Foram inauguradas ainda, uma biblioteca e uma exposição em homenagem a esta mulher negra, mãe solteira de três filhos, migrante, catadora de papel que há 45 anos vivia numa das primeiras favelas paulistanas (ARAÚJO, 2001).

Como objetivo geral, a instituição propõe-se a "promover o reconhecimento, valorização, preservação e difusão da arte, da história e da memória cultural brasileira, tendo como referência a presença luso afro brasileira, indígena e africana”. E em sua proposta:

Sendo um museu brasileiro, o Museu Afro Brasil não pode deixar de ser também um museu da diáspora africana, pois a presença do negro, no Brasil e nas Américas, é indissociável da experiência de desenraizamento de milhões de seres humanos arrancados aos seus lugares de origem graças à instituição da escravidão. É a escravidão que, na diáspora, força o contato e o intercâmbio entre membros de diferentes nações africanas e produz as mais diversas formas de assimilação entre suas culturas e as de seus senhores, bem como de resistência à dominação que estas lhes impõem. O Museu Afro Brasil é um museu da diáspora e, como tal, deverá registrar não só o que de africano ainda existe entre nós, mas o que foi aqui apreendido, caldeado e transformado pelas mãos e pela alma do negro, a miscigenação e a mestiçagem que contribuíram para a originalidade de nossa brasilidade (ARAÚJO, 2001).

Em Sergipe a mestiçagem se consolidou com a presença de portugueses e holandeses, ampliada com os indígenas já encontrados, e as populações sudanesas e bantas, a partir do século XVI, aumentando no século XVIII, se concentrando na região do Cotinguiba, região canavieira do Estado, onde se encontra o município de Laranjeiras, considerado o "Berço da Cultura Negra do Estado de Sergipe”. Mormente, em Laranjeiras localiza-se o Museu Afro-brasileiro de Sergipe (MABS), inaugurado em janeiro de 1976 e oficializado em fevereiro do mesmo ano, pelo decreto $\mathrm{n}^{\circ}$ 3339 (LODY, 2004). Foi um projeto museológico elaborado pelo jornalista e memorialista Luiz Antônio Barreto, tendo como concepção interpretativa e expográfica a narrativa da história do povo 
negro à partir da dinâmica da escravidão levada à termo pela dominação branca. É um olhar branco sobre o negro e termina reforçando estereótipos de vitimização ou exotismo cultural.

Outras representações da cultura afro-brasileira podem ser encontradas em exposições itinerantes no Museu do Homem Sergipano (MUHSE) em Aracajú.

\section{Quadro Demonstrativo de Exposições Temporárias realizadas no Museu do Homem Sergipano entre 1981 e 2000, com ênfase na abordagem da cultura afro-descendente.}

\begin{tabular}{|c|c|c|}
\hline Temática & Título & Idéia Central \\
\hline Negro & O Negro e o Trabalho & $\begin{array}{l}\text { Mostrar como } 100 \text { anos após a } \\
\text { abolição a raça continua como } \\
\text { elemento classificatório } \\
\text { importante na divisão social de } \\
\text { trabalho no Brasil. Evidenciar o } \\
\text { lugar do negro na força de } \\
\text { trabalho e relacionar através de } \\
\text { rituais, a ligação entre o } \\
\text { simbolismo e o trabalho. }\end{array}$ \\
\hline Negro & O Negro em Sergipe & $\begin{array}{l}\text { Apresentar uma série de } \\
\text { conhecimentos sobre o negro } \\
\text { em Sergipe, dentro de uma visão } \\
\text { sócio-cultural e histórica ampla, } \\
\text { buscando relações entre África, } \\
\text { Brasil e Sergipe. }\end{array}$ \\
\hline Ritual Negro & O Nagô de Bilina & $\begin{array}{l}\text { Ampliar a discussão sobre o } \\
\text { papel do negro na diversidade } \\
\text { cultural do Brasil através da } \\
\text { religião e especificamente de um } \\
\text { terreiro de Nação Nagô. }\end{array}$ \\
\hline Folclore & $\begin{array}{l}\text { Lambe-Sujo e Caboclinhos: } \\
\text { Negros e Índios em Rituais } \\
\text { Folclóricos }\end{array}$ & $\begin{array}{l}\text { Mostrar como em diferentes } \\
\text { formas de linguagem, se } \\
\text { apresentam as etnias, sendo no } \\
\text { caso, entre negros e índios. }\end{array}$ \\
\hline Folclore & $\begin{array}{l}\text { Danças e Folguedos sergipanos: } \\
\text { Uma expressão de Identidades }\end{array}$ & $\begin{array}{l}\text { Mostrar as danças e folguedos } \\
\text { sergipanos como resultantes do } \\
\text { encontro de tradições culturais } \\
\text { africanas, européias e } \\
\text { americanas. }\end{array}$ \\
\hline
\end{tabular}

Fonte: SAMPAIO, 2000. (Anexos)

O MUHSE foi criado por um movimento - durante a gestão do Reitor professor José Aloísio de Campos, liderado por grupo de professores do então Departamento de Ciências Psicológicas, Sociológicas e Antropológicas (DCPSA) da Universidade Federal de Sergipe (UFS) em 
$1976^{5}$, dentre eles as professoras Luiza Maria Gonçalves e Beatriz Góis Dantas - com o objetivo de preservar e divulgar a memória da sociedade sergipana (SILVA, 2012, p.35).

Muitos museus, como o de Aracajú, têm adotado como organização de seu acervo um fio condutor temático capaz de agregar conjuntos de uma mesma origem, não peças dispersas, mas objetos que foram recuperados num contexto definido, representando o mundo rural ou urbano, as formas de trabalho e economia, os elementos culturais e políticos presentes em distintos grupos sociais e étnicos, dentro de sua própria historicidade, permitindo a construção de um olhar etnográfico.

\section{Museus como territórios contestados: debates sobre as novas perspectivas nas exposições sobre a cultura afro-brasileira.}

Trabalhos de antropólogos, sociólogos, historiadores e demais pesquisadores (ABREU, 1996; BREFE, 2005; SANTOS, 2006) caminharam na direção da construção de uma interpretação da História e do Brasil a partir do estudo das coleções, da história institucional e dos discursos museográficos. Uma atenção especial tem sido dada à educação não-formal nesses espaços devido ao volume e qualidade de experiências realizadas. Análises de processos comunicativos, estudos

\footnotetext{
${ }^{5}$ Entre 1973 a 1976 há um conjunto de ações para a criação do Museu, quando então ele nasce como Museu de Antropologia - órgão suplementar da PROEX-UFS, mas sem uma estrutura física. Com o Dec.08 - DPSA/DCS criase o setor de Antropologia que sob a liderança da professora Beatriz Góis Dantas realiza exposições itinerantes sobre a temática indígena e a cerâmica sergipana. Na década de 1980 o CULTART cede uma sala onde Hélia Maria de Paula Barreto, professora do Departamento de Ciências Sociais torna-se responsável pela Sala de Cultura Popular. Em poucos anos a sala é fechada e do final da década de 1980 ao início da década de 1990, a discussão sobre a criação de uma instância museológica se faz presente, e com as contribuições da professora Cristina Bruno cria-se o Núcleo Museológico, abrigado na sala do CCBS/UFS que passa a acondicionar as exposições itinerantes que anteriormente foram organizadas pela professora Beatriz Góis Dantas. Pouco tempo depois, o local é destituído de sua funcionalidade e o Núcleo é transferido para uma sala do Hotel Palace, sendo mais tarde transferido para o antigo prédio da Faculdade de Ciências Econômicas na Praça Camerino. Nesse espaço as professoras Hélia Barreto e Verônica Nunes retomam o contato com a professora Cristina Bruno, coincidindo com o momento da publicação do livro "Textos para a História de Sergipe" (um livro de autoria de professores dos Departamentos de História e Ciências Sociais, coordenado por Diana Maria de Faro Leal Diniz, com textos de Beatriz Góis Dantas, Diana Maria de Faro Leal Diniz, Lenalda Andrade Santos, Maria Andrade Gonçalves, Maria da Glória Santana de Almeida e Teresinha Alves de Oliva) aproveita-se para se organizar o projeto museológico que seria responsável pela criação do Museu do Homem Sergipano, inaugurado em 1996. Entretanto as portarias ainda em vigor eram do Museu de Antropologia e somente com a resolução 07/2000/Consu de 28 de abril o museu é oficialmente reconhecido como Museu do Homem Sergipano. No período da Sala de Cultura Popular a professora Hélia Maria de Paula Barreto foi diretora, mais tarde o professor Luiz Alberto assume a direção do Museu de Antropologia, na década de 1990 a 2004 ocorre o retorno da professora Hélia Maria de Paula Barreto à direção, de 2005 a junho de 2009, assume a direção a professora Terezinha Alves de Oliva (DHI) e de junho de 2009 até 2012 assume a professora Verônica Nunes (NMS) (NUNES, 2010).
} 
quantitativos de público e descrições de atividades pedagógicas se destacam na construção de estratégias de transmissão dos significados/representações sociais ao público mais amplo.

Salienta-se que o museu educa por meio da tridimensionalidade e, nesse sentido, a exposição e todas as linguagens que a compõem educam não somente o olhar, mas também sobre a História. Assim: a Educação Patrimonial é um instrumento de "alfabetização cultural" que possibilita ao indivíduo fazer a leitura do mundo que o rodeia, levando-o à compreensão do universo sociocultural e da trajetória histórico-temporal em que está inserido. Este processo leva ao reforço da auto-estima dos indivíduos e comunidades e à valorização da cultura brasileira, compreendida como múltipla e plural (HORTA, 1999, p.6).

O autor Fernando Catroga conduz a uma reflexão importante ao analisar a relação dialética entre memória e história. De acordo com o autor, uma produz a outra, não há hierarquia. Ambas operam com a seletividade, a verossimilhança, a representação e a tridimensionalidade do tempo, ou seja, com a inclusão do projeto de futuro.

É necessária ainda a compreensão da fonte em sua dimensão social e histórica, refletindo sobre os sentidos de sua conservação, sua organização e seu pertencimento à instituição. No caso do museu, é preciso pesquisar a história das fontes, ou seja, as cadeias operacionais dos processos museológicos envolvendo a seleção, a aquisição, a doação, a conservação preventiva, a concepção e a exposição.

Myriam Sepúlveda destaca que "os museus têm a função de legitimar um imaginário junto ao público e, quando cumprem sua função, não conseguem modificar este imaginário com facilidade" (SANTOS, 2006, p.56). No caso dos museus históricos essa tarefa é ainda mais importante, pois é preciso refletir sobre as expectativas do público em relação a eles, assim como os processos de reconhecimento.

Em um momento em que as políticas públicas nacionais incentivam o papel dos museus como agentes de democratização e de valorização das culturas em sua multiplicidade (criação de uma Política Nacional de Cultura e do próprio Instituto Brasileiro de Museus - IBRAM), em que os discursos sociais apontam para um olhar positivo para um passado integrador, em que as escolas saúdam o dever de memória, os museus históricos precisam estar continuamente se repensando. Perante desafios monumentais, que incluem diversidades culturais, o uso de linguagens distintas, a consolidação da acessibilidade física e cultural, os museus históricos precisam dialogar com a atividade de elaboração do conhecimento histórico (ALENCAR, 1987). 
Nesse sentido, a História Cultural tem por principal objetivo identificar o modo como em diferentes lugares e momentos uma realidade social é construída, pensada, dada a ler. Voltando-se para a vida social, esse campo pode tomar por objeto as formas e os motivos de suas representações e pensá-las como análise do trabalho de representação das classificações e das exclusões que constituem as configurações sociais e conceituais de um tempo ou de um espaço. No entanto, a História Cultural deve ser entendida como o estudo dos processos com os quais se constrói um sentido, tornando-se aberto o espaço a ser decifrado (CHARTIER, 2002, p.17).

Ressalte-se que em março de 2008, ocorreu o $1^{\circ}$ Fórum de Museus de Sergipe, no auditório da Biblioteca Pública Epifânio Dantas, resultando na sistematização e encaminhamento de uma carta com propostas e diretrizes da política de Museus em Sergipe.

Ao explorar seu processo de construção de memórias, o museu histórico pode ensejar a apropriação da linguagem e da ferramenta pelos diferentes grupos sociais, fomentando o diálogo, e não apenas o reconhecimento. Jesus Barbero (1999), por exemplo, propõe o museu como espaço de choque e negociação cultural, de articulação entre a imagem e a ausência. A dimensão dialógica propicia aos museus e às suas ações educativas densidade para discutir o pluralismo e o processo litigioso das memórias. É necessário prever, incluir e expor formas diferentes de perceber o tempo e a história, principalmente de povos que estiveram silenciados durante um longo período como os de matriz africana.

\section{Considerações Finais}

Em tempos de usos das novas tecnologias, o uso da virtualidade promovendo interfaces entre os museus afro-brasileiros e os usuários podem gerar instrumentos preciosos para uma narrativa expográfica renovada. Ainda reforçando esse encontro entre história, educação, identidade e novas mídias, também a projeção de documentários, como, por exemplo, "Quanto vale ou é por Quilo” (2005) e outros documentários amadores postados no Youtube podem ser ferramentas importantes para a composição de uma nova linguagem no campo da afirmação positiva da identidade negra no Brasil.

É necessário identificar e reconhecer os bens culturais enquanto portadores de valor testemunhal, envolvendo sua preservação dentro de uma prática cultural imiscuída de valor político e heterogêneo (ARANTES, 1987). 
Patrimônio, herança, ou seja, aquilo que é adquirido por transmissão, vindo de gerações anteriores. Esse "patrimônio" compartilhado por um grupo é composto por valores e julgamentos que são expressos e representados em práticas e manifestações culturais com todo um sistema de significados que lhe é subjacente. Assim, se a tradição é vista como algo imutável, isso faz com que o patrimônio cultural seja visto também como algo cristalizado no tempo e no espaço.

Por isso a necessidade de tornar esse patrimônio "plástico", maleável, flexível, adaptado aos novos tempos e às demandas dos grupos sociais que tem conquistado voz e vez na sociedade brasileira das últimas décadas.

\section{Referências Bibliográficas:}

ABREU, Regina. A fabricação do imortal: memória, história e estratégias de consagração no Brasil. Rio de Janeiro: Rocco: Lapa, 1996.

ALENCAR, Vera Maria Abreu de. Museu-educação: se faz caminho ao andar... Dissertação (Mestrado em Educação). Pontifícia Universidade Católica do Rio de Janeiro, Rio de Janeiro, 1987.

ANICO, Marta. A pós-modernização da cultura: patrimônio e museus na contemporaneidade. Horizontes Antropológicos, Porto Alegre, ano 11, n. 23, pp. 71-86, jan./jun. 2005.

ARANTES, Antonio Augusto. Documentos históricos, documentos de cultura. In: Revista do Patrimônio Histórico e Artístico Nacional. Rio de Janeiro: SPHAN, no 22, pp. 48-55. 1987.

ARAÚJO, E. (org). A mão afro-brasileira. São Paulo: Tenengue, 1988.

Para nunca esquecer. Negras Memórias, memórias de negros. Brasília: Ministério da Cultura, 2001.

BARBERO, Jesus-Martin. Cambios en la percepción de la temporalidad. In: MINISTÉRIO DA CULTURA. Museo y memória nacional. Colômbia, 1999.

BAUDRILLARD, Jean. O sistema dos objetos (1929-2007).Tradução: Zumira Ribeiro Tavares. 5 ed. São Paulo:Perspectiva, 2008.

BLOCH, Marc. Apologia da História ou o Ofício do Historiador. Rio de Janeiro: Jorge Zahar Editor, 2001. 
BREFE, Ana Claudia Fonseca. O Museu Paulista: Affonso de Taunay e a memória nacional. São Paulo: Editora Unesp, 2005.

CATROGA, Fernando. Memória, história e historiografia. Coimbra: Quarteto Edições, 2001.

CHAGAS, Mário. Memória e poder: focalizando as instituições museais. In: Interseções. Rio de Janeiro, UERJ, ano 3, n. 2, pp.5-23. jul./dez. 2001.

CHARTIER, Roger. História Cultural: entre práticas e representações. Tradução de Maria Manuela Galhardo. Aglés - Portugal: Difel, 2002.

COSTA, Carina Martins. A escrita de clio nos temp(l)os da mnemósime: olhares sobre materiais pedagógicos produzidos pelos museus. In: Educação em Revista, Belo Horizonte, n. 47, pp. 217 240, jun. 2008.

CUNHA, Marcelo N. Bernardo da; NUNES, Eliane; SANDES, Juipurema A. Sarraf. Nina Rodrigues e a Constituição do Campo da História da Arte Negra no Brasil. In: Gazeta Médica da Bahia. 2006; 76(Suplemento 2), pp. 23-28.

ENNE, A. L. S. ; TAVARES, Cristiane . Memória, identidade e discurso midiático: uma revisão bibliográfica. In: Novo Enfoque Revista Eletrônica da Pró Reitoria de Pesquisa da Ucb, Rio de Janeiro, n.1, 2004.

FONSECA, Maria Cecília Londres. O Patrimônio em processo: trajetória da política federal de preservação no Brasil. Rio de Janeiro: UFRJ: IPHAN,1997.

GEERTZ, Clifford. A interpretação das culturas. Rio de Janeiro: Guanabara Koogan, 1989.

GEERTZ, Clifford. O Saber Local. Petrópolis, Rio de Janeiro: Vozes, 2000.

HORTA, Maria de Lourdes; GRUNBERG, Eveline; MONTEIRO. Guia básico de educação patrimonial. Petrópolis: Museu Imperial: IPHAN, 1999.

LODY, R.G. da Mota. O negro no museu brasileiro: construindo identidades. Rio de Janeiro: Bertrand Brasil, 2004. 
MATTTOSO, Katia M. de Queirós. A opulência na província da Bahia In: ALENCASTRO, Luiz Felipe de (org.). História da Vida Privada no Brasil. Império: a corte e a modernidade nacional. São Paulo, Companhia das Letras, 1997, pp. 143-179.

NORA, Pierre. Entre memória e história: a problemática dos lugares. In: Revista Projeto História. São Paulo: Departamento de História de Pontifícia Universidade Católica de São Paulo / PUC-SP, no.10, 1993, pp. 07-28.

NUNES, Verônica M. M. O Museu do Homem Sergipano. In: Revista Patrimônio e Memória. UNESP - FCLAs - CEDAP, v.6, n.2, pp. 78-96, dez.2010.

PIO, Leopoldo Guilherme. Musealização e cultura contemporânea. In: Musas: Revista Brasileira de Museus e Museologia, Rio de Janeiro, ano 2 n. 2, pp. 48-57, IPHAN, 2006.

POLLAK, Michel. Memória e Identidade Social. In: Estudos Históricos, Rio de Janeiro, vol. 5, n. 10, 1992. pp.1-15.

PROST, Antoine. Doze lições sobre a história. Belo Horizonte: Autêntica Editora, 2008.

PROUST, Marcel. Em busca do tempo perdido. Rio de Janeiro: Ediouro, 2004.

RODRIGUES, Raymundo Nina. Os africanos no Brasil. São Paulo: Ed. Nacional; Brasília: Ed. da Universidade de Brasília, 1988. 
SANTOS, Myriam Sepúlveda. A escrita do passado em museus históricos. Rio de Janeiro: Garamond, 2006.

SAMPAIO, Roberta B. O museu do homem sergipano: uma realidade em construção. Monografia. São Cristóvão: UFS, 2000.

SILVA, Marcos A. Além das coisas e do imediato: cultura material, história imediata e ensino de história. In: Revista Tempo. No 21, pp. 82-96, Niterói: UFF, 2007. pp. 82-96.

SILVA, Valdineide Maria da. Coleção Carrapicho: a trajetória das cerâmicas expostas no Museu do Homem Sergipano (1983-2012). Monografia de Graduação em Museologia. Universidade Federal de Sergipe: UFS-NMS, 2012.

SLENES, Robert. Malungu, ngoma vem! África encoberta e descoberta no Brasil. Luanda, Angola: Museu Nacional da Escravatura, INPC, Ministério da Cultura. 1995. 